\title{
A Study to determine the Prevalence of Malocclusion and Chief Motivational Factor for Desire of Orthodontic Treatment in J aipur City, India
}

\author{
${ }^{1}$ Ruchi Sharma, ${ }^{2}$ Kuldeep Sharma, ${ }^{3}$ Dhruv Yadav, ${ }^{4}$ A bhilasha Choudhary, ${ }^{5}$ S wapnil Singh
}

\section{ABSTRACT}

Background: Prevalence of malocclusion varies in different parts of a diverse country like India.

\begin{abstract}
Aims: To determine the prevalence of malocclusion in population of J aipur city, R ajasthan, India, as well as subjects views regarding the most important factor for seeking orthodontic treatment by patients who have malocclusion.
\end{abstract}

\begin{abstract}
Materials and methods: The sample consisted of 700 subjects (373 males and 327 females) with age group of 15 to 30 years. Subjects were randomly selected and none of them had received orthodontic treatment previously. The subjects who showed bilateral Angle's class I molar relationship with acceptable overjet, overbite and well-aligned arches or minimal crowding were considered to have normal occlusion. The subjects with malocclusion were classified into four groups according to Angle's classification, i.e. class I, class II division 1, class II division 2 and class III malocclusions.
\end{abstract}

Results: About $74.57 \%$ of population was found to have malocclusion. Among these subjects, $52.57 \%$ subjects were diagnosed with class I malocclusion, $12.57 \%$ with class II division 1 malocclusion, $8 \%$ with class II division 2 and remaining $1.42 \%$ had class III malocclusion. No statistically significant differences were found between male and female subjects.

Conclusion: Among class I malocclusion characteristics, Angle's class I type 1 malocclusion was statistically significantly found to be the most prevalent type of malocclusion. As far as the most importantfactor for seeking orthodontic treatment was determined, a desire of enhancing facial appearance followed by a desire of attaining straight teeth was considered to be the chief motivational factor among this population.

\footnotetext{
${ }^{1,2}$ Senior Lecturer, ${ }^{3}$ P ostgraduate Student (3rd Year)

${ }^{4}$ Postgraduate Student(2nd Year), ${ }^{5} \mathrm{P}$ ostgraduate Student (1stYear)

${ }^{1}$ Department of Orthodontics and Dentofacial Orthopedics NIMS Dental College and Hospital, NIMS University, J aipur Rajasthan, India

${ }^{2-4}$ Department of Orthodontics and Dentofacial Orthopedics Rajasthan Dental College and Hospital, J aipur, Rajasthan, India

${ }^{5}$ Department of Oral and Maxillofacial S urgery, Daswani Dental College, Kota, Rajasthan, India
}

Corresponding Author: RuchiS harma, Senior Lecturer, Department of Orthodontics and Dentofacial Orthopedics, F-1, Anand Enclave, Modi Nagar, Panchsheel Colony, Ajmer Road J aipur-302006, Rajasthan, India, P hone: 9461752741, e-mail: dr.sharmaruchi@ rediffmail.com
Keywords: J aipur, India, Malocclusion, Prevalence.

How to cite this article: Sharma R, Sharma $K$, Yadav D, Choudhary A, Singh S. A Study to determine the Prevalence of Malocclusion and Chief Motivational Factor for Desire of Orthodontic Treatment in J aipur City, India. World J Dent 2015; $6(2): 87-92$.

\section{Source of support: Nil}

Conflict of interest: None

\section{INTRODUCTION}

Dental caries and periodontal disease are admittedly the most common oral diseases and are one of the main oral health problems, affecting the quality of life of the individuals. ${ }^{1}$ It has been observed that malocclusion is the third most important condition in the ranking of oral health problems, outranked only by dental caries and periodontal disease. In a diverse country like India, the prevalence of malocclusion varies widely in different parts of the country as they can arise due to disparities in ethnicity, dietary habits, religious beliefs and nutritional status. Malocclusions strongly influence the facial and dental appearance of an individual, and hence impose a very significant impact on an individual's physical, social and psychological well-being.

Some individuals with dentofacial disharmonies seeking treatment experience a level of psychological distress that may warrant psychological/psychiatric intervention. ${ }^{2}$ In this era of evidence based dentistry, epidemiological evaluation facilitates gathering information about the prevalence of malocclusion and current traits regarding orthodontic treatment in a particular population and then comparison of this information with the standards of dental healthcare which is important not only for healthcare providers but also for healthcare consumers.

\section{AIMS AND OBJECTIVES}

Therefore, the aim of this study was to determine the prevalence of malocclusion in population of Jaipur city, Rajasthan, India, with the adjoining aim being the assessment of subjects' views regarding the most important factor for seeking orthodontic treatment by patients having malocclusion. 


\section{MATERIALS AND METHODS}

The sample consisted of 700 subjects (including 373 males and 327 females) of age range between 15 and 30 years. The subjects were selected randomly from the various regions of Jaipur city. All subjects were assigned for clinical evaluation by a single operator and occlusal relationships were assessed at centric occlusion which was achieved by asking the subjects to swallow and then to bite their teeth together as explained in Figure 1. The cheeks were fully retracted to obtain a direct lateral view of the dentition on each side and dental models (Fig. 2) were also used.

\section{Inclusion Criteria}

- All permanent teeth present in each arch (except third molars) and in a sufficient state of eruption.

- No systemic disease or congenital syndrome.

\section{Exclusion Criteria}

- Dentition with missing molars or carious teeth or any deciduous/primary teeth.

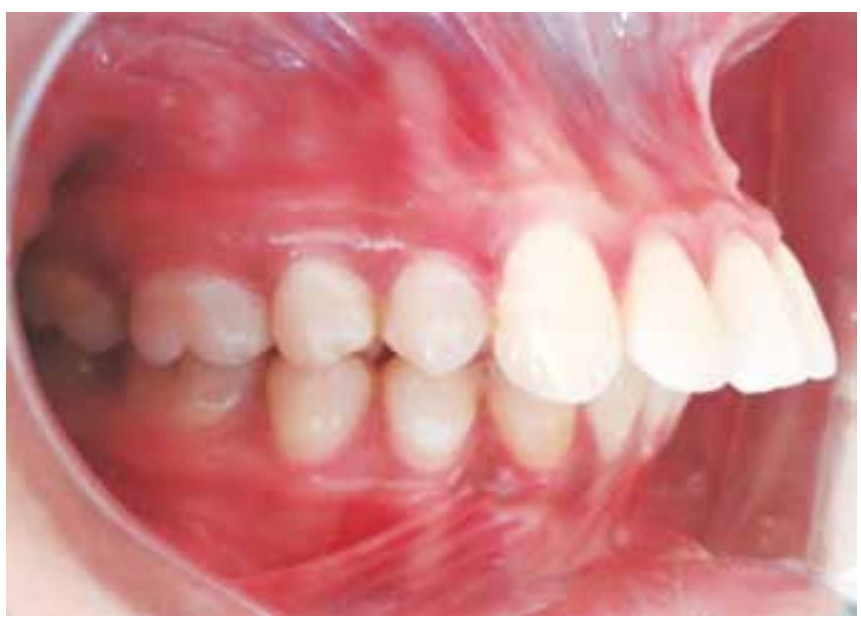

Fig. 1: Clinical evaluation of occlusal relationships at centric occlusion

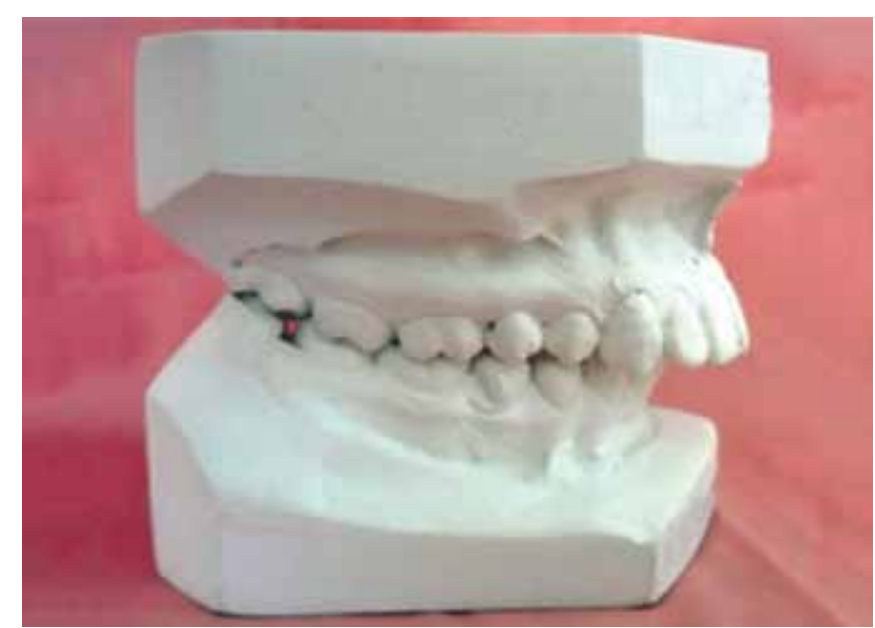

Fig. 2: Dental model for assessment of occlusion
- Dentition with large coronal restoration which might have altered the crown shape and its size.

- End to end cuspal molar relationships or others (not full cusp relationships).

The subjects who showed bilateral Angle's class I molar relationship with acceptable overjet and overbite and well-aligned arches or minimal crowding on clinical evaluation were included in normal occlusion group.

Thereafter, the individuals with malocclusion were classified into three groups according to Angle's classification which is the most widely accepted classification system of malocclusion, i.e. class I, class II and class III malocclusions. ${ }^{3}$ The criteria for inclusion were as follows:

- Class I malocclusion: Bilateral Angle's class I molar relationship (mesiobuccal cusp of maxillary first permanent molar occluding in the buccal groove of mandibular first permanent molar) with one or more of these characteristics described according to Dewey's modification of Angle's classification: crowded incisors or labial canines (Angle's class I type 1 malocclusion), protruded maxillary incisors (Angle's class I type 2 malocclusion), anterior end to end occlusion or anterior cross bite (Angle's class I type 3 malocclusion), unilateral or bilateral posterior cross bite (Angle's class I type 4 malocclusion), mesial drift of molars (Angle's class I type 5 malocclusion). Other than these characteristics anterior or posterior open bite, generalized spacing, mid-line diastema and deep anterior overbite associated with Angle's class I molar relationship were also included in class I malocclusion.

- Class II malocclusion: Bilateral Angle's class II molar relationship (disto-buccal cusp of maxillary first permanent molar occluding in the buccal groove of mandibular first permanent molar) with proclined maxillary incisors and increased overjet (Angle's class II division 1 malocclusion) or with retroclined maxillary central incisors and proclined lateral incisors (Angle's class II division 2 malocclusion).

- Class III malocclusion: Bilateral Angle's class III molar relationship (mesiobuccal cusp of maxillary first permanent molar occluding in the interdental space between mandibular first and second permanent molars) with end to end incisor relationship or with normal incisor relationship with incisors in crossbite relationship.

A proforma consisting of question 'According to you what is the most important factor because of which people with crooked teeth seek orthodontic treatment?' was given to each subject to determine the subject's view regarding the main reason to seek orthodontic treatment by patients having malocclusion. It was divided into 
dental esthetic reasons, facial appearance reasons, speech and periodontal problem reasons and functional reasons for demanding orthodontic treatment.

Thus, the data obtained in this manner were then tabulated and analyzed statistically.

\section{RESULTS}

Among 700 participants, 373 cases (53.28\%) were men and 327 cases $(46.71 \%)$ were women. The occlusal characteristics with gender distribution of the subjects are explained in Table 1, Graphs 1 and 2.

It is clear from the Table 1 that prevalence of malocclusion in the population was $74.57 \%$ while normal occlusion was found in $25.42 \%$ subjects. The prevalence of class I malocclusion was $52.57 \%$ being highest among all subjects followed by class II division 1 malocclusion with $12.57 \%$, class II division 2 with $8 \%$, and class III malocclusion with $1.42 \%$ being the least prevalent which was found to be highly significant $(p<0.001)$ on statistical analysis with Chi-square test. No significant differences ( $p>0.05)$ were observed in between male and female participants. The percentage distribution of class I malocclusion characteristics is explained in Table 2.
The most common malocclusion among class I malocclusion characteristics was Angle's class I type 1 malocclusion (26.57\% of overall population) which was found to be statistically significant ( $p<0.05$ ). Graph 3 also explains the relative prevalence proportions among various characteristics of class I malocclusions.

The most important factor for desire of orthodontic treatment was also determined in this study. Table 3, Graphs 4 and 5 reveal that majority of subjects had a view that a desire of enhancement in facial appearance (47\%) followed by a desire of attaining straight teeth (42\%) would be the most important factor for seeking orthodontic treatment by patients having malocclusion. On statistical application with Chi-square test, this finding was found to be statistically highly significant. No statistically significant differences were detected between male and female subjects regarding their views.

\section{DISCUSSION}

The data from the study show that prevalence of malocclusion was to be $74.57 \%$ in Jaipur population. These findings are similar to the findings of Das et $\mathrm{al},{ }^{4}$ who reported $71 \%$ of prevalence of malocclusion in Bangalore.

Table 1: Occlusal characteristics with gender distribution of the subjects

\begin{tabular}{|c|c|c|c|c|c|c|}
\hline \multirow[b]{2}{*}{ Malocclusion } & \multicolumn{2}{|c|}{ Male } & \multicolumn{2}{|c|}{ Female } & \multicolumn{2}{|c|}{ Total } \\
\hline & Number & Percentage & Number & Percentage & Number & Percentage \\
\hline Class I malocclusion & 220 & 58.98 & 148 & 45.25 & 368 & 52.57 \\
\hline $\begin{array}{l}\text { Class II division } 1 \\
\text { malocclusion }\end{array}$ & 33 & 8.84 & 55 & 16.81 & 88 & 12.57 \\
\hline $\begin{array}{l}\text { Class II division } 2 \\
\text { malocclusion }\end{array}$ & 31 & 8.31 & 25 & 7.64 & 56 & 8.00 \\
\hline Class III malocclusion & 9 & 2.41 & 1 & 0.30 & 10 & 1.42 \\
\hline Normal occlusion & 80 & 21.44 & 98 & 29.96 & 178 & 25.42 \\
\hline Total & 373 & 100 & 327 & 100 & 700 & 100 \\
\hline
\end{tabular}

For malocclusion comparison, Chi-square $=25.373$ with 3 degree of freedom $(p=0.000 * *$; For male and female comparison, Chi-square $=6.361$ with 4 degree of freedom $(p=0.174)$

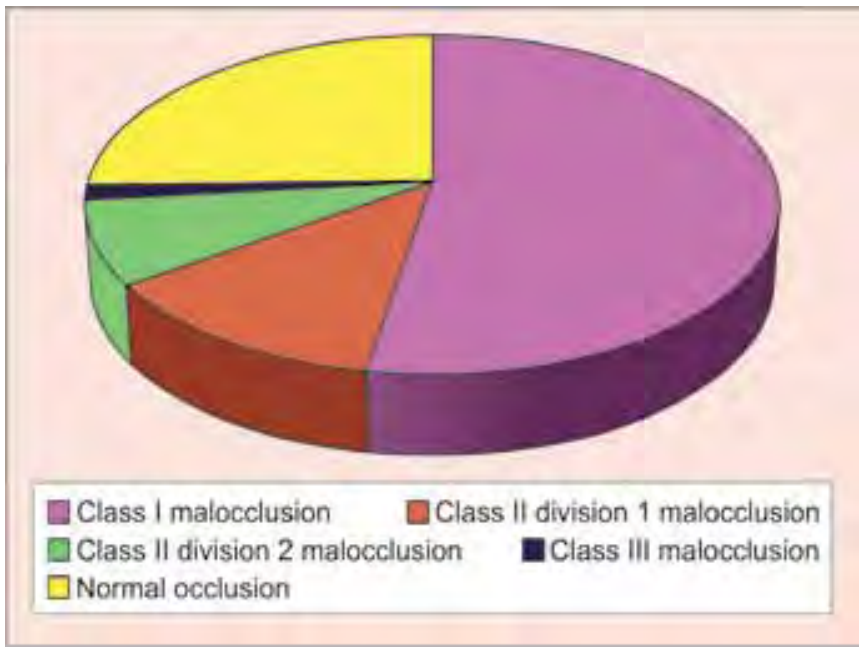

Graph 1: Distribution of normal and malocclusion in overall population

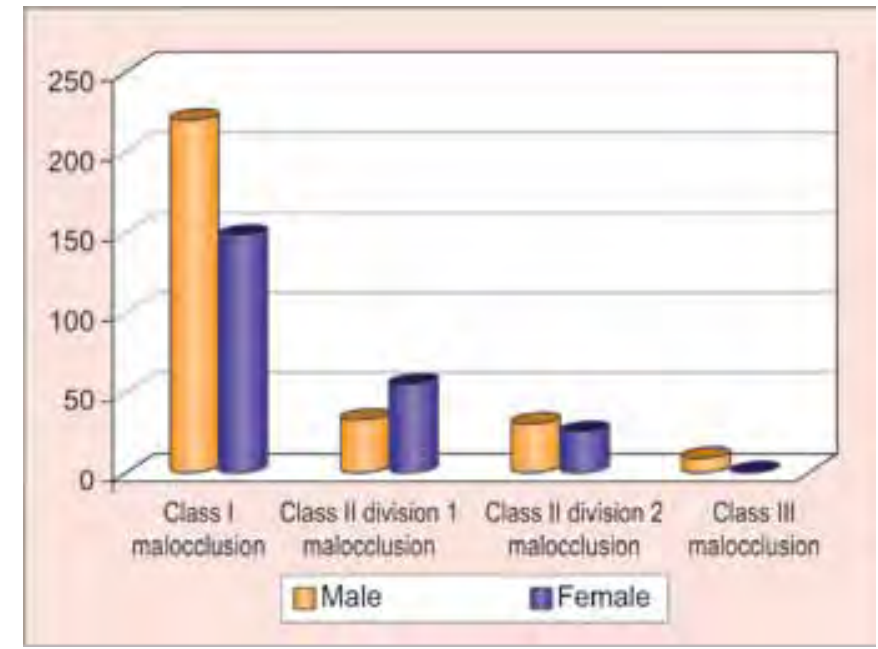

Graph 2: Gender distribution of different malocclusions 
Table 2: Distribution of class I malocclusion with percentage

\begin{tabular}{lll}
\hline Class I malocclusion characteristics & Number & Percentage \\
\hline $\begin{array}{l}\text { Angle's class I with anterior or } \\
\text { posterior open bite }\end{array}$ & 20 & 2.85 \\
Angle's class I with deep bite & 58 & $8.28^{* *}$ \\
Angle's class I with generalized & 24 & 3.42 \\
spacing & 34 & 4.85 \\
Angle's class I with midline diastema & 34 & $26.57^{*}$ \\
Angle's class I type 1 & 186 & 5.14 \\
Angle's class I type 2 & 36 & 0.57 \\
Angle's class I type 3 & 4 & 0.85 \\
Angle's class I type 4 & 6 & 52.57 \\
\hline Total & 368 &
\end{tabular}

This study is in disagreement with the findings of Prasad et $\mathrm{al}^{5}$ who reported of $51.5 \%$ incidence of malocclusion with $95 \%$ class I, $4 \%$ class II, $0.9 \%$ class III malocclusion in the age group of 5 to 15 years in Bangalore and also with the findings of Kharbanda et $\mathrm{al}^{6}$ who found $45 \%$ prevalence of malocclusion in 10 to 13 years old children in Delhi.

An ethnic trend can also be observed in the prevalence of type of malocclusion in India from north to south of India. The prevalence of class II malocclusion in Bangalore ${ }^{5}$ and Thiruvananthapuram ${ }^{7}$ is reported nearly $5 \%$ which is lower as compared to the 10 to $15 \%$ class II malocclusion in Delhi and Haryana ${ }^{6}$ and this study. In addition, the southern population has ethnic affinity for bimaxillary protrusion. The findings of this study is in disagreement with a survey ${ }^{7}$ done in southern Indian city of Thiruvananthapuram in age group 12 to 15 which reported $49.2 \%$ overall prevalence of malocclusion. Rao $^{8}$ reported $23.0 \%$, prevalence rate of class I malocclusion, $4.5 \%$ of class II and $1.3 \%$ of class III malocclusion in 511 Udupi subjects with age range of 5 to 15 years.

Thus, the prevalence of malocclusions is quite high in population of Jaipur city which indicates an earnest need for implementing preventive as well as corrective measures in the society especially for those malocclusions which are more prevalent and ensures the role of the orthodontists in there amelioration. It is also clear from the findings of a study ${ }^{9}$ done by Sharma et al which aimed at the evaluation and assessment of the basic attitude and beliefs of the general masses of Jaipur regarding routine oral healthcare practices, a lack of knowledge and negligence toward oral health was found as majority of

Table 3: Factors for seeking orthodontic treatment

\begin{tabular}{llll}
\hline \multirow{2}{*}{$\begin{array}{l}\text { Factors for seeking } \\
\text { orthodontic treatment }\end{array}$} & \multicolumn{3}{c}{ Number of respondents } \\
\cline { 2 - 4 } & Female & Male & Total \\
\hline Attaining straight teeth & $125(38.22 \%)$ & $169(45.30 \%)$ & $294(42.00 \%)$ \\
Enhancement of facial appearance & $150(45.87 \%)$ & $179(47.98 \%)$ & $329(47.00 \%)$ \\
Improvement in speech & $4(1.22 \%)$ & $3(0.80 \%)$ & $7(1.00 \%)$ \\
Improvement in function & $14(4.28 \%)$ & $7(1.87 \%)$ & $21(3.00 \%)$ \\
Improvement in self confidence & $31(9.48 \%)$ & $13(3.48 \%)$ & $44(6.28 \%)$ \\
Periodontal problem & $3(0.91 \%)$ & $2(0.53 \%)$ & $5(0.71 \%)$ \\
\hline Total & $327(100 \%)$ & $373(100 \%)$ & $700(100 \%)$ \\
\hline
\end{tabular}

For total group comparison, Chi-square $=57.908$ with 5 degree of freedom ( $\left.p=0.000^{* *}\right)$; For male and female group comparison, Chi-square $=4.805$ with 5 degree of freedom $(p=0.502)$

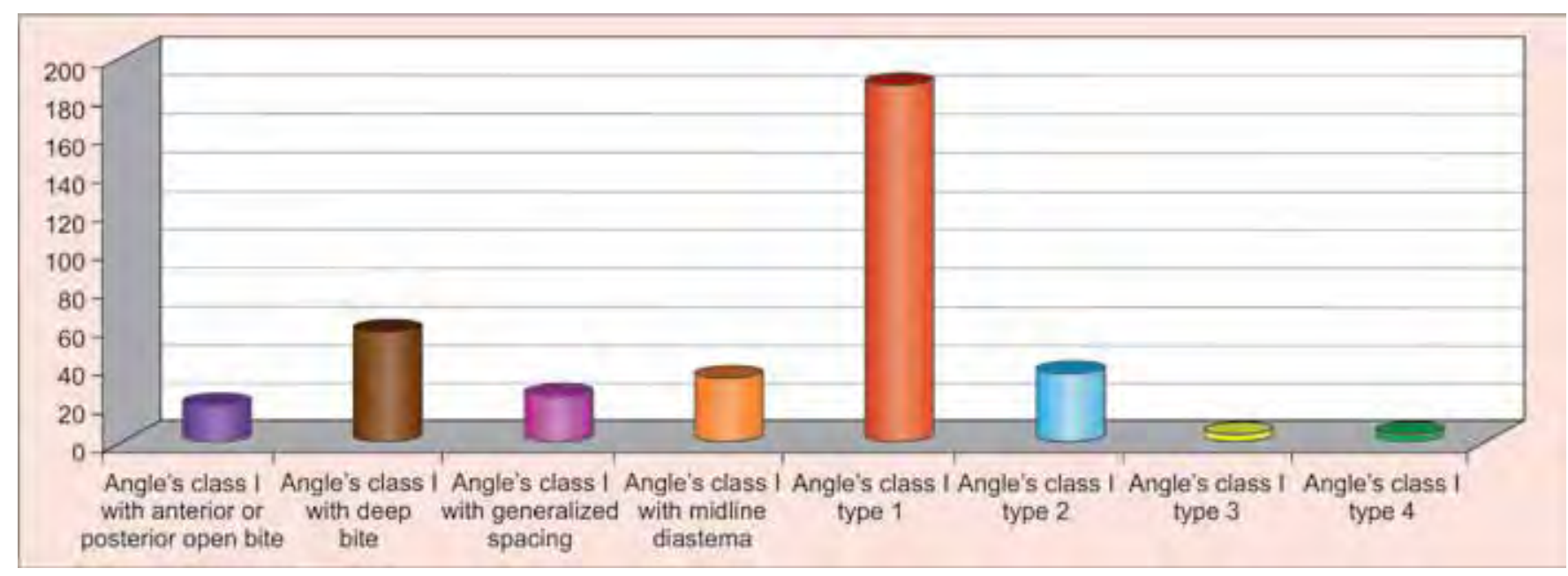

Graph 3: Distribution of class I malocclusion characteristics 


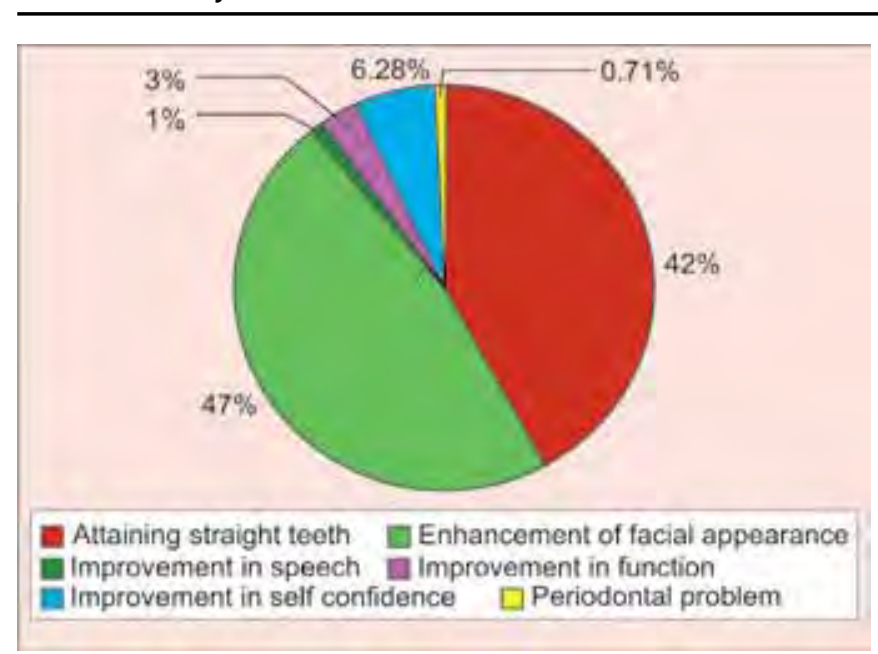

Graph 4: Factors for seeking orthodontic treatment

people do not prefer visiting the dentists, unless having some dental emergencies like pain.

As far as the subject's perspective was appreciated regarding the major directive forces that may drive any individual for seeking orthodontic treatment for malocclusion, a desire to improve the overall facial appearance was found to be the prime motivating factor, followed by a desire to attain straightened teeth. These findings are in disagreement with that of Pabari et $\mathrm{al}^{10}$ wherein a wish to improve dental appearance was found to be the main motivating factor, followed by a wish to improve overall facial appearance. Thus, it is important to know the current traits regarding orthodontic treatment prevailing among a particular population as a number of factors may influence the subject's decision to undergo orthodontic treatment, such as gender, age, social, cultural, psychological and personal factors, etc.

\section{CONCLUSION}

Epidemiological evaluations of dental diseases, such as malocclusion, are a prerequisite for systematic planning of preventive and therapeutic measures for confronting such problems and for assessing the current traits regarding orthodontic treatment in a particular population. ${ }^{11}$ The study was directed toward the achievement of these goals. The conclusions which can be drawn from this study are as follows:

- The prevalence of malocclusions was found to be $74.57 \%$ in Jaipur population.

- Class I malocclusion had the highest prevalence $(52.57 \%)$ followed by class II division 1 , class II division 2 and class III malocclusion being the least prevalent which was found to be statistically highly significant. No statistically significant differences were found between male and female subjects.

Among class I malocclusion characteristics, Angle's class I type 1 was the most common malocclusion which was also found to be statistically significant.

Majority of subjects had a view that a desire of enhancement in facial appearance followed by a desire of attaining straight teeth would be the most important factor for seeking orthodontic treatment by patients having malocclusion. This finding was found to be statistically highly significant with no statistically significant differences detected between male and female subjects regarding their views.

The prevalence of malocclusion and the chief motivational factor are very important elements in determining and planning appropriate levels of orthodontic services. Further studies are required to provide accurate estimates of the orthodontic treatment need in Indian population and the relationship between prevalence of malocclusion and the chief motivational factor for seeking orthodontic treatment.

\section{ACKNOWLEDGMENT}

We would like to acknowledge all the study subjects for their cooperation.

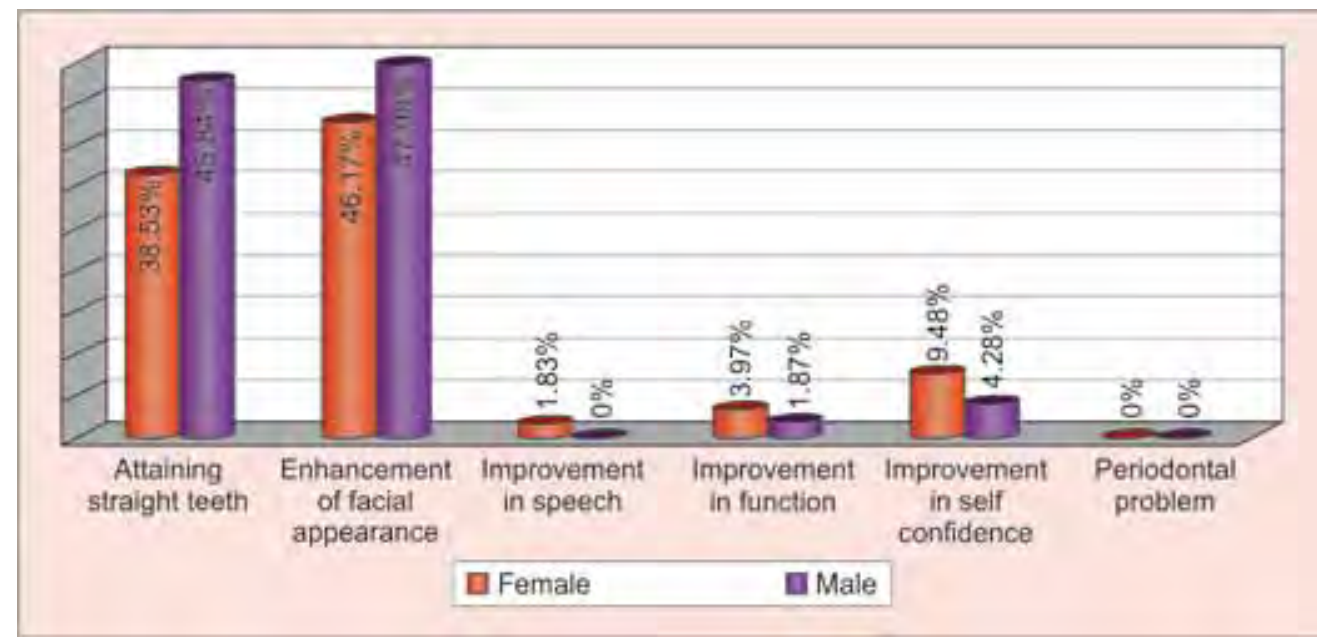

Graph 5: Gender distribution of factors for seeking orthodontic treatment 


\section{REFERENCES}

1. Gomes AP, da Silva EG, Gonçalves SH, Huhtala MF, Martinho FC, Gonçalves SE, Torres CR. Relationship between patient's education level and knowledge on oral health preventive measures. Int Dent Med J Adv Res 2015;1: 1-7.

2. Phillips C, Bennett M E, Broder HL. Dentofacial disharmony: psychological status of patients seeking treatment consultation. The Angle Orthodontist 1998;68(6):547-556.

3. Angle EH. Classification of malocclusion. Dent Cosmos 1899;41:248-264, 350-357.

4. Das UM, V Reddy D. Prevalence of malocclusion among school children in Bangalore, India. Int J Clin Ped Dent 2008;1(1):10-12.

5. Prasad AR, Shivaratna SC. Epidemiology of malocclusion: a report of a survey conducted in Bangalore city. J Ind Orthod Soc 1971;3(3):43-55.
6. Kharbanda OP. Orthodontics_-diagnosis and management of malocclusion and dentofacial deformities. Elsevier. 2nd ed. 2013. p. 26-27.

7. Jacob PP, Mathew CT. Occlusal pattern study of school children (12-15 years) of Tiruvananthapuram city. J Ind Dent Assoc 1969;41:271-274

8. Rao DB, Hegde AM, Munshi AK. Malocclusion and orthodontic treatment need of handicapped individuals in South Canara. India Int Dent J 2003;53(1):13-18.

9. Sharma R, Singh S, Rajmani H, Degra H. An evaluation of the current oral hygiene practices and attitude towards oral health in the population of Jaipur, India. Int Dent Med J Adv Res 2015;1:1-6.

10. Pabari S, Moles DR. Assessment of motivation and psychological characteristics of adult orthodontic patients. Am J Orthod Dentofac Orthop 2011;140(6):e263-e272.

11. Jain S, Gupta A, Jain D. Estimation of sample size in dental research. Int Dent Med J Adv Res 2015;1:1-6. 